\title{
Cultural Imperatives of Prosocial Behaviour: A Redefinition of Volunteerism in Nigeria
}

\section{Chiedozie Okechukwu Okafor}

Department of Psychology, Federal University, Ndufu-Alike, Ikwo, Ebonyi State, Nigeria

Email address:

calldozie@yahoo.co.uk, chiedozie.okafor@funai.edu.ng

\section{To cite this article:}

Okafor Chiedozie Okechukwu. Cultural Imperatives of Prosocial Behaviour: A Redefinition of Volunteerism in Nigeria. Humanities and Social Sciences. Vol. 3, No. 5, 2015, pp. 230-233. doi: 10.11648/j.hss.20150305.20

\begin{abstract}
Volunteerism has been widely defined as a long-term, planned pro-social behavior that benefits strangers, and which occur within an organizational setting (e.g, Penner, 2002). This definition seems to divorce volunteering from by-stander intervention in an emergency situation, which does involve helping strangers. The present paper contends that this definition of volunteerism does not consider cultural imperatives. For example, the paper argues that the indigenous help practices attendant in a collectivist society such as Nigeria do not always locate strangers, and could fellow up help efforts from an emergency to a long-standing non-emergency end. The paper, therefore, posits that any meaningful research and discussion on volunteerism in Nigeria should give credence to cultural foundations of prosocial behaviour such as kinship and in-group empathy. This, hopefully, will improve the possibilities of crime control, terrorism reduction and poverty alleviation.
\end{abstract}

Keywords: Volunteerism, Kinship, Empathy, Help, Prosocial Behaviour

\section{Introduction}

Within the domain of psychology, there is a long history of interest on when, why and how people willingly give away their time, efforts and money to help others. Prosocial behaviour is a broad term that is used to define these voluntary behaviours intended to benefit another (Eisenberg, Fabes \& Spinrad, 2006). Prosocial behaviour was not extensively studied until 1970, and since then has been a great area of interest and focus of many studies due to a desire to understand human nature and motivation involved in prosocial behaviours (Eisenberg, et al., 2006).

Researches on prosocial behaviour in the past had focused primarily on a very specific kind of helping behaviour bystanders intervening to provide immediate and short-term help to a physically distressed stranger (Latané \& Nida, 1981). In recent times, more attention has been given to prosocial behaviours that continue for an extended period of time - sustained prosocial actions. According to Penner (2002), there are a number of different kinds of behaviour that might be classified as sustained prosocial action (e.g., working as a firefighter, caring for a chronically-ill loved one) including volunteerism. Thus, he defined volunteerism as a long-term, planned, prosocial behaviour that benefit strangers, and which occur within an organization setting.
Musick and Wilson (2008) hold that volunteering is a form of altruistic behavior. The association between volunteering and altruism is understandable in light of the fact that a great deal of volunteering involves providing direct service to other people, including comforting the needy and the sick (Chambré, 1995) without expectations of reward. Clearly, a desire to help others without payment is critical to doing any form of volunteer work. Yet, a combination of altruism and self interest is common (Gidron, 1983; van Til, 1985, Androni, 1989). Midlarsky (1991) points out that in the process of helping other people, individuals themselves benefit. Some psychologists and sociologists (eg. Wilson \& Musick, 1997b) have considered volunteering as a social activity rather than an altruistic one, meaning that people engage in volunteer work for the pleasure of interacting with other people in addition to any values or altruistic motivations they may have. Other studies have found that participation in any social activity correlates positively with volunteering, including activities that have no prosocial content (Wilson \& Musick, 1997a; Wilson, 2000). This evidence indicates that an interest in spending time with others, independent of altruistic or values motivation plays a role in motivating people to volunteer. Thus, a volunteer activity may not be altruistic.

Penner (2002); Penner, Midili and Kegelmeyer (1997) 
suggested that volunteerism has four attributes that define it and serve to distinguish volunteerism from other kinds of prosocial action. First, it is a planned action; people think and weigh their options before they make the decision to volunteer. In this respect, volunteerism can be contrasted with bystander interventions in emergencies, in which immediate, affective reactions play a primary role in people's decisions about whether or not to intervene. Second, volunteerism is a long-term behaviour; most people who volunteer continue this activity for an extended period of time (Independent Sector, 1999; Penner \& Finkelstein, 1998). Again, this can be contrasted with bystander interventions, which are usually quite time limited.

Third, as Omoto and Snyder (1995) have pointed out too, volunteering involves "non-obligated" helping. Omoto and Snyder (1995) argued that in most forms of helping, the potential helper feels personally obligated to offer aid to the potential recipient. This feeling of obligation, according to Penner (2004) may be evoked by the verbal and nonverbal behaviours of a distressed stranger as in the classic bystander intervention paradigm. However, more commonly, the sense of obligation results from some long-term personal association between the helper and recipient, including friendship, familial or kinship ties. In contrast, according to Penner (2004); Omoto and Snyder (1995), there are rarely any personal ties or associations between volunteers and recipients of their help. Indeed, in many instances, individual volunteers and the people who ultimately benefit from their action never even meet. Much more frequently, the actual point of contact is between the volunteer and an organization that benefits the targets of the volunteers' efforts. Thus a feeling of personal obligation to some particular individual is absent from most decisions to volunteer. Therefore, those who volunteer are compelled by will. Penner (2004) went further to state that one of the important attributes of volunteering is that it occurs within an organizational context. That is, the vast majority of people who work as volunteers do this as part of a service or religious organization; the latter being the most common kind of volunteering (Independent Sector, 2002). Thus, whereas phenomena such a bystander interventions and the provision of social support may be explained by models that include only interpersonal variables, Penner (2004) insists that an adequate explanatory model of volunteering must include organizational and structural variables also.

\subsection{Who is a Volunteer}

Rochester (2006) posits that there are some variations regarding who is least likely to be considered as a volunteer, but money, and less freedom have definite impacts on people's perception of who is a volunteer across all regions. On the other hand, there were differences of culture and context such as different views about the legitimacy of some of the "perks" of volunteering. She further stated that while there is a measure of agreement about the core characteristics of volunteering, it seems there is not a single, simple, objective definition which enables us to draw a clear line between what is volunteering and what is not. Instead, we need to look more closely at the fuzziness of some of the boundaries. The first of these is the question of structure. The Home Office/Citizenship surveys (2003; 2005) distinguish between three kinds of participation in community and voluntary activities: "civic participation", defined as contact with an MP or other elected representative or a public official; attending a public meeting or rally; taking part in a public demonstration or protest; or signing a petition; "informal volunteering", defined as giving unpaid help as an individual to people who are not relatives; and "formal volunteering", defined as giving unpaid help through groups, clubs or organizations to benefit other people or the environment (for example, the protection of wildlife or the improvement of public open spaces). The informal volunteer could be a bystander, different from the classical bystander in the sense that help to the victim may be prolonged. Similarly, in African, particularly in the South-Eastern Nigeria, when people are concerned about a particular victim, even if the victim was first met at an emergency, some people follow up the victim's "recovery" progress, at least by asking: "how do you do?" This is more so when the victim is a kin or a neighbour.

\subsection{Volunteerism or Kin and Neighbour Concerns}

Conceptually, van Emmerick (2005) observed that different types of helping behaviours can be thought of as a $4 \times 2$ matrix of helping behaviours that can be either formal at work/formal at home; informal at work/informal at home; at either the level of individual/ small group (e.g. taking care of kin and neighbours) or communities (e.g. volunteering), respectively. Within the area of work and family studies, two types of helping behaviours are especially relevant. First, volunteerism, such as cooking for drug addicts; second, taking care of kin and neighbours (Penner, 2004). Usually, both types of helping behaviours are long-term behaviours and they usually involve thoughtful decisions of people to seek out situations in which they can provide help (Penner, Midili \& Kegelmeyer, 1997), although it is possible that people might just help a neighbour once or volunteer once at a shelter. Further, these types of helping behaviors are essentially carried out to produce and maintain the well-being and integrity of others. According to van Emmerick (2005), volunteerism and taking care of kin and neighbours differ also in several dimensions. For instance, these helping behaviours can vary according to the degree of familiarity with the recipients: Taking care of kin and neighbours is directed at familiar and close recipients. In contrast, volunteerism is frequently directed at non-familiar recipients (van Emmerick, Stone \& Jawahar, 2003). Frequently, volunteers do not know in advance who they help, since they are matched with recipients by service organizations (Omoto \& Snyder, 1995).

\section{Culture Perspectives in Volunteerism}

A very different perspective on the nature of volunteering 
is found in many parts of the world, notably in Africa. Lyons, Wijkstrom and Clary (1998) term this the "civil society paradigm". Its academic roots are in political science and sociology and its focus is on associations - organizations which depend entirely on volunteers. Rather than "nonprofits" that serve the public, those who work within the civil society paradigm are interested in those that serve their members - organisations that are the product of people's ability to work together to meet shared needs and address common problems (Lyons et al, 1998). Whereas the nonprofit paradigm treats volunteering as unpaid labour, the civil society alternative describes it as activism and sees it as a force for social change. In African countries, a great diversity of indigenous forms of volunteering co-exists next to "western" ways (Anheier \& Salamon, 2001). For example, in Nigeria and Ghana, like in many African countries, "Village association" of volunteers (e.g. The Age Grade Associations) can be found on nearly every rural and urban community. Rooted in the local culture, they provide communal services and assistance in times of need. Sometimes, these associations, like the Boys Scout, are modeled after their American or British counterparts (Anheier, 1987). The nature of these help movement may be appreciated when one observes the surrounding cultural and social practices (which limit its scope) as implied by the individualism-collectivism perspectives.

\section{Individualism-Collectivism Perspectives}

Many cross-cultural psychologists believe that the most important construct for explaining the social psychological patterns of culture is "individualism" versus "collectivism". According to Triandis (1995) individualistic societies are characterized by an orientation to the individual and their nuclear family, whereas collectivistic societies give highest priority to the welfare of one or larger collectives (see Triandis, 1995). At this level of explanation, it might be predicted that collectivist societies should be more likely to attend to the needs of strangers. Where indigenous volunteer movements operate in countries with "collectivist culture", they may frequently target unfamiliar recipients.

As recent discussions of individualism-collectivism (e.g. Levin, Norenzayan \& Philbrick, 2001) point out, equating collectivism with concern for individuals outside of one's relevant collective is not necessarily true. Thus, as argued by Sethi, Lepper and Ross (1999), collectivist cultures often focus less attention on outsiders. Starting with the volunteer teams that are rooted in local cultures (example, the Age Grade in the South-East), Nigerians seem to hardly demonstrate charity beyond their traditional regions. This seems to have informed the idea of coming home whenever there is need to execute humanitarian community projects. No wonder Nigerians in Diaspora come home to donate infrastructures and health facilities even when such facilities are needed by the countries of their residence. It may be very rare, if non-existing, to see infrastructure erected by a person of a particular town for people of another town, unless related by blood or marriage. Usually, where such things are found, they are mediated by the efforts of the government or foreign donors.

\section{Conclusion}

In view of the above argument, the present researcher contends that the current definition of volunteerism do not consider cultural imperatives. For example, as observed by Anheier and Salamon (2001), volunteering is rooted in the local cultures in many African countries, notably, Nigeria and Ghana. No doubt, cultural practices play upon empathic concerns to determine the direction of the volunteer movement and the nature of help rendered. The recent terrorist attack in Chibok, Borno State of Nigeria, where the fate of the over 300 abducted school girls were first left in the hands of their parents and relatives was a demonstration of the inability of a collectivist culture to focus help beyond ingroup arrangements. In the South-Eastern Nigeria (a more collectivist society), the "Age Grades", as volunteer movements, hardly operate outside their towns of origin. This means that helping kin and neighbours is an important aspect of formal volunteerism in African, particularly in Nigeria where family ties and affiliations are highly valued. Therefore, while it may be advisable to design volunteer efforts and help along kinship, neighbourliness and common affiliations, this paper encourages all Nigerians to be more charitable in extending helping hands to people in need of help irrespective of affiliation. This is necessary especially in the face of political and religious crisis.

Therefore, a working definition of volunteerism needs neither be restricted to "a long-term planned prosocial behaviour" nor to a focus on "strangers". To this end, the present researcher therefore defines volunteerism as a willful prosocial behaviour that benefits people in need with or without their solicitation, which builds upon the helpers' orientation and occurs within the context of cultural expectations.

\section{References}

[1] Anheier, H. K., \& Salamon, L. M. (2001). Volunteering in cross-national perspective: Initial comparisons. Civil Society working paper 10, London School of Economics and Political Science.

[2] Anheier, H. K. (1987). Indigenous voluntary associations, non-profits and development in Africa. In W. Powell, The Non-profit Sector: A Research Handbook. New Haven: Yale University Press.

[3] Chambré, S. M. (1984). Is volunteering a substitute for role loss in old age? An empirical test of activity theory. The Gerontologist, 24 (3), 292-298.

[4] Chou, K. (1998). Effects of age, gender, and participation in volunteer activities on the altruistic behaviour of Chinese adolescents. The Journal of Genetic Psychology, 159, 195-201. 
[5] Eagly, A. H., \& Crowley, M. (1986). Gender and helping behaviour: A meta-analytic view of the social psychological literature. Psychological Bulletin, 100, 283-308.

[6] Home Office (2005), Together we can: a government action plan led by the Home Office, London: Home Office.

[7] Home Office/Compact Working Group (2003). Volunteering Compact Code of Good Practice, London: Home Office.

[8] Independent Sector (2002). Giving and volunteering in the United States. Washington DC: Author.

[9] Latané, B., \& Nida, S. (1981). Ten years of research on group size and helping. Psychological Bulletin, 89, 308-324.

[10] Levine, R. V., Norenzayan, A., \& Philbrick, K. (2001). Crosscultural differences in helping strangers. Journal of CrossCultural Psychology, 32 (5), 543-560.

[11] Lyons, M., Wijkstrom, P., \& Clary, E. (1998), Comparative studies of volunteering: what is being studied. Voluntary Action, 1(1), 45-54.

[12] Midlarsky, E. (1991). Helping as coping. Review of Personality and Social Psychology, 12, 238-264.

[13] Okun, M. A., \& Michel, J. (2006). Sense of community and being a volunteer among the young-old. Journal of Applied Gerontology, 25(2), 173-188

[14] Olawoye, J. E., Omololu, F. O., Aderinto, Y., Adeyefa,I., Adeyemo, D., \& Osotimehin, B. (2001). Social construction of manhood in Nigeria: Implication for male responsibility in reproductive health. Ibadan: Social Science Reproductive Health Research Network.

[15] Omoto, A., \& Snyder, M. (1995). Sustained helping without obligation: Motivation, longevity of service and perceived attitude change among AIDS volunteers. Journal of Personality and Social Psychology, 68, 671-687.

[16] Omoto, A., \& Snyder, M. (2002). Considerations of community: The context and process of volunteerism. American Behavioural Scientist, 45, 846-867.

[17] Park, J. Z., \& Smith, C. (2000). To whom much has been given: Religious capital and community voluntarism among churchgoing Protestants. Journal for the Scientific Study of Religion, 39(3), 272-286.

[18] Penner, L. A. (2002). The causes of sustained volunteerism: An interactionist perspective. Journal of Social Issues, 58 (3), 447-467.

[19] Penner, L. A. (2004). Volunteerism and social problems:
Making things better or worse? Journal of Social Issues, 60 (3), 645-666.

[20] Penner, L. A., \& Finkelstein, M. A. (1998). Dispositional and structural determinants of volunteerism. Journal of Personality and Social Psychology, 74, 525-537.

[21] Penner, L. A., Midili, A. R., \& Kegelmeyer, J. (1997). Beyond job attitudes: A personality and social psychology perspective on the causes of organizational citizenship behaviour. Human Performance, 10, 111-132.

[22] Putnam, R. (2000). Bowling alone: The collapse and revival of American community. New York: Simon and Schuster.

[23] Rochester, C. (2006). Making sense of volunteerism: A literature review. The Commission on the Future of Volunteerism. England: Volunteering England.

[24] Sethi, S., Lepper, M., \& Ross, L. (1999). Independence from whom? Interdependence with whom? Cultural perspectives on ingroups versus outgroups. In D. Miller and D. Prentice (Eds.), Cultural divides. Thousand Oaks, CA: Sage.

[25] Triandis, H. (1995). Individualism and collectivism. Westview: Boulder, Co.

[26] van Emmerick, H. (2005). Helping behaviours: Volunteerism and taking care of kin. Unpublised paper, Department of Sociology, Utrecht University, The Netherlands.

[27] van Emmerick, H., Stone, T. H., \& Jawahar, J. (2003). The relationship between altruism and helping behaviours: Some moderating effects of burnout. Proceedings of the $63^{\text {rd }}$ Annual Meeting of the Academy of Management (Best Papers proceedings). Seattle.

[28] van Til, J. (1985). Mixed motives: Residues of altruism in an age of narcissism. In Moore, L. F., (Ed.), Motivating volunteers: How the rewards of unpaid work can meet people's needs. Vancouver, BC: Vancouver Volunteer Centre, pp. 243-261.

[29] Wilson, J., \& Musick, M. A. (1997b). Who Cares? Towards an Integrated Theory of Volunteer Work. American Sociological Review, 62(5), 694-713.

[30] Wilson, J. (2000). Volunteering. Annual Review of Sociology, 26, 215-40.

[31] Wilson, J., \& Janoski, T. (1995). The contribution of religion to volunteer work. Sociology of Religion, 56(2), 137-153.

[32] Wilson, J., \& Musick, M. A. (1997a). Work and volunteering: The long arm of the job. Social Forces, 76, 251-272. 